\title{
Synthesis and gas sensing properties of membrane template-grown hollow $\mathrm{ZnO}$ nanowires
}

\author{
Jae-Hyoung Lee ${ }^{1}$, Jin-Young Kim, Jae-Hun Kim ${ }^{1}$, Ali Mirzaei ${ }^{2}$, Hyoun Woo Kim²* and Sang Sub Kim ${ }^{2^{*}}$
}

\begin{abstract}
One-dimensional, hollow nanostructured materials are among the most promising materials for sensing applications owing to their high surface area that facilitates the adsorption of target gases. Accordingly, for gas sensing studies, hollow ZnO nanowires (NWs) with different surface areas were successfully synthesized herein by using polycarbonate membranes with different pore sizes as templates, and deposition of $\mathrm{ZnO}$ via the atomic layer deposition technique. The sensing properties of the synthesized hollow $\mathrm{ZnO} N W s$ were examined for $\mathrm{CO}$ and $\mathrm{NO}_{2}$, revealing their comparative sensing performances with $\mathrm{ZnO}$ nanomaterials-based sensors reported in literature. This study highlights a novel way of synthesizing hollow $\mathrm{ZnO}$ NWs by using membrane template and their promising sensing properties as well.
\end{abstract}

Keywords: Hollow, ZnO, Nanowire, Membrane, Surface area, Gas sensor

\section{Introduction}

Because of increasing concerns about air pollution, public security, and the high standards of modern life, gas detection has gained increasing importance $[1,2]$. Metal-oxide gas sensors are most commonly used for the detection of ambient gases based on their high response, fast and dynamic characteristics, easy fabrication, portability, and cheapness [3]. However, the performance of these sensors must be enhanced to meet the demands of the high standards of living. One promising approach for enhancing the gas-detection capability of metaloxide-based gas sensors is to increase the surface area of the sensor [4]. In fact, a higher surface area generally results in greater availability of sites for gas adsorption, and accordingly, higher performance. Many researchers have investigated high-surface-area metal-oxides such as nanofibers (NFs) [5], nanorods [6], nanowires (NWs) [7], and hierarchical [8] and porous materials [9] for gas sensing applications. In order to further increase the

\footnotetext{
*Correspondence: hyounwoo@hanyang.ac.kr; sangsub@inha.ac.kr ${ }^{1}$ Department of Materials Science and Engineering, Inha University, Incheon 22212, Republic of Korea

2 Division of Materials Science and Engineering, Hanyang University, Seoul 04763, Republic of Korea
}

surface areas of such nanomaterials, hollow nanostructured nanomaterials can be employed. Such morphologies offer more adsorption sites as they possess inner and outer surfaces, meaning that the surface-to-volume ratio almost doubles compared with that of the normal solid counterparts; therefore, higher sensing performance is expected [10].

In our previous work [11], we fabricated hollow $\mathrm{ZnO}$ NFs with different diameters via the electrospinning method. It was found that $\mathrm{ZnO}$ NFs with smaller diameters were more sensitive to both reducing and oxidizing gases than those with larger diameters. In another study [12], we found that the sensing performance of $\mathrm{ZnO}$ hollow NFs depended on their wall thickness, where the ZnO hollow NFs with thinner walls showed better sensing performance. More recently [13], we reported $\mathrm{TiO}_{2} /$ $\mathrm{ZnO}$ inner/outer double-layer hollow NFs that exhibited sensitive and selective detection of reducing gases. Zhang et al. [14] compared the $\mathrm{CO}$ gas sensing properties of hollow and normal $\mathrm{TiO}_{2} \mathrm{NFs}$; the hollow $\mathrm{TiO}_{2} \mathrm{NFs}$ showed better sensing performance because of the effect of the increased surface-to-volume ratio derived from generation of the inner surfaces. Park et al. [10] reported that a hollow ZnO NFs sensor showed much higher sensitivity 
to $\mathrm{NO}_{2}$, when compared to normal $\mathrm{ZnO} \mathrm{NFs}$, owing to the increased surface area of the former.

In most of these literature studies on hollow nanostructures, the focus was placed on hollow NFs and less attention has been paid to other hollow nanostructures such as hollow NWs. NW gas sensors exhibit many inspiring characteristics such as (i) ultra-sensitivity and fast response time, (ii) higher selectivity and stability, (iii) light weight, (iv) low power consumption, and (v) wireless communication applicability [15]. Therefore, it is of importance to increase the performance of NW gas sensors by increasing the surface area through the fabrication of hollow NWs. Accordingly, in this work, we report the novel synthesis, characterization, and sensing performance of hollow ZnO NWs prepared using cyclopore polycarbonate membranes (with different pore sizes) as templates with subsequent deposition of $\mathrm{ZnO}$ via atomic layer deposition (ALD). The membrane templates were removed by combustion at $450{ }^{\circ} \mathrm{C}$ over $4 \mathrm{~h}$. Scanning electron microscope (SEM) images demonstrate formation of the hollow $\mathrm{ZnO}$ NWs. Gas sensing tests towards $\mathrm{CO}$ and $\mathrm{NO}_{2}$ gases reveal the higher performance of the gas sensors with higher surface area. The sensing mechanism is also discussed in detail.

\section{Experiment}

\subsection{Synthesis of hollow $\mathrm{ZnO}$ NWs}

The hollow $\mathrm{ZnO}$ NWs were prepared on $\mathrm{SiO}_{2}(200 \mathrm{~nm}$ thick)-grown $\mathrm{Si}$ (100) substrates using the membranetemplate method and ALD technique. For synthesis of the hollow ZnO NWs, cyclopore polycarbonate membranes (Whatman) were used as templates. The two membrane-templates had a diameter of $25 \mathrm{~mm}$ and thickness of $13 \mu \mathrm{m}$, and respective pore diameters of 0.4 and $1 \mu \mathrm{m}$. $\mathrm{ZnO}$ was deposited on these membranes via a conventional ALD technique, as described in our previous paper [16]. ALD was performed by sequential exposure of the cyclopore polycarbonate membranes to diethylzinc $\left(\mathrm{Zn}\left(\mathrm{C}_{2} \mathrm{H}_{5}\right)_{2}\right.$ or DEZn) $)$ and $\mathrm{H}_{2} \mathrm{O}$ vapor, separately by $\mathrm{N}_{2}$ purge at a flow rate of $100 \mathrm{sccm}$ at $80{ }^{\circ} \mathrm{C}$. The ALD process consisted of $0.1 \mathrm{~s}$ pulse of DEZn, $20 \mathrm{~s}$ of exposure of the cyclopore polycarbonate membranes to DEZn, $40 \mathrm{~s}$ of $\mathrm{N}_{2}$ purge followed by a $2 \mathrm{~s}$ pulse of $\mathrm{H}_{2} \mathrm{O}$, $30 \mathrm{~s}$ exposure to $\mathrm{H}_{2} \mathrm{O}$, and a final $60 \mathrm{~s} \mathrm{~N}_{2}$ purge. After 250 ALD cycles, $\mathrm{ZnO}$ films with $50 \mathrm{~nm} \mathrm{ZnO}$ thickness were deposited on the cyclopore polycarbonate membranes. To finally remove the membrane template, heat treatment at $450{ }^{\circ} \mathrm{C}$ for $4 \mathrm{~h}$ was performed under ambient atmosphere. Figure 1 shows a schematic illustration of the process for fabricating the hollow $\mathrm{ZnO}$ NWs.

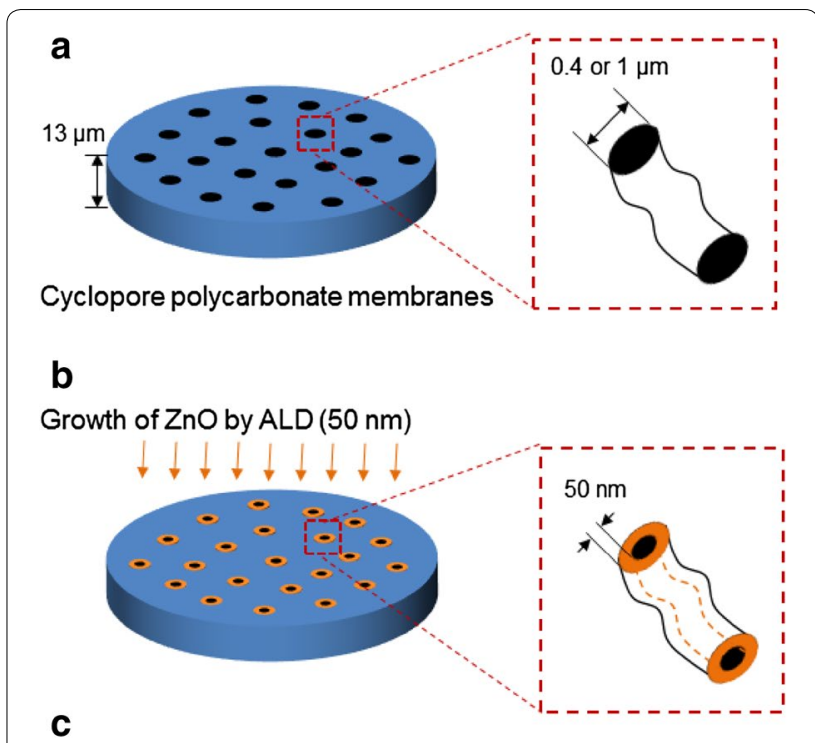

Burn out of membrane $\left(450^{\circ} \mathrm{C}\right)$

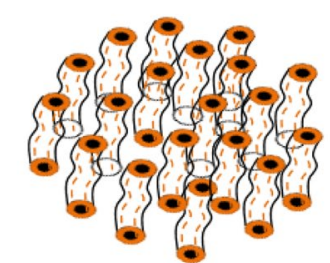

Fig. 1 Schematic illustration of steps used for the preparation of hollow ZnO NWs. a Cyclopore polycarbonate membranes. $\mathbf{b}$ Growth of $\mathrm{ZnO}$ by ALD $(50 \mathrm{~nm})$. c Burn out of membrane $\left(450^{\circ} \mathrm{C}\right)$

\subsection{Characterization}

The morphology of the synthesized hollow $\mathrm{ZnO}$ NWs was studied by field emission scanning electron microscopy (FE-SEM, S-4300SE, Hitachi). The phase and crystallinity were examined by X-ray diffraction (XRD, X'pert MPD PRO, Philips), and the specific surface areas were measured by Brunauer-Emmett-Teller (BET) analysis.

\subsection{Gas sensing test}

The process for fabrication of the sensors is described in detail in our previous publications $[17,18]$. We applied the interdigitated electrode on the surface of the sensing layer deposited on the substrate. In other words, the interdigitated electrode was made on top of the sensing layer by sputtering with a metal shadow mask. For the interdigitated electrode, $\mathrm{Ti}(\sim 50 \mathrm{~nm}$ in thickness) and $\mathrm{Pt}$ $(\sim 150 \mathrm{~nm})$ double layers were sequentially deposited on the sensing layer via sputtering using an interdigital electrode shadow mask. 
The sensing properties of the hollow $\mathrm{ZnO} \mathrm{NW}$ sensors were investigated in the presence of $\mathrm{CO}$ (reducing gas) and $\mathrm{NO}_{2}$ (oxidizing gas). The sensing measurements were performed at different temperatures using a home-made gas dilution and testing system. To avoid any possible variation in the sensing properties, the gas concentration was controlled by changing the mixing ratio of the dry air-balanced target gas and dry air through accurate mass flow controllers, with total flow rate of $500 \mathrm{sccm}$. The response of the fabricated sensors was determined as follows:

$$
\begin{array}{ll}
R=R_{a} / R_{g} & \text { For CO gas } \\
R=R_{g} / R_{a} & \text { For } \mathrm{NO}_{2} \text { gas }
\end{array}
$$

where $R_{a}$ and $R_{g}$ are the resistances in the absence and presence of the target gas, respectively.

\section{Results and discussion}

\subsection{Structural and morphological study}

The XRD patterns of the hollow $\mathrm{ZnO}$ NWs are shown in Fig. 2. The diffraction peaks at $2 \theta$ values of $31.72^{\circ}, 34.38^{\circ}$, $36.26^{\circ}, 47.61^{\circ}, 56.63^{\circ}, 62.90^{\circ}, 66.35^{\circ}, 67.98^{\circ}$, and $69.11^{\circ}$ could be indexed to the (100), (002), (101), (102), (110), (103), (200), (112), and (201) lattice planes of $\mathrm{ZnO}$ with the wurtzite hexagonal crystal structure (JCPDS Card No. 36-1451). No other diffraction peaks were observed in the XRD patterns, indicating successful removal of the polycarbonate membrane templates upon heat treatment at $450{ }^{\circ} \mathrm{C}$.

The morphologies of the hollow $\mathrm{ZnO}$ NWs were observed by FE-SEM. Figure 2a, b show typical FE-SEM images of the hollow $\mathrm{ZnO} \mathrm{NWs}$ with different surface areas (i.e., 9.33 and $10.17 \mathrm{~m}^{2} \mathrm{~g}^{-1}$ ) prepared from the membranes with pore sizes of 1 and $0.4 \mu \mathrm{m}$, respectively. As shown in Fig. 2a, the hollow ZnO NWs synthesized using the membrane with a pore diameter of $1 \mu \mathrm{m}$ had a relatively smooth surface morphology. The inset in this figure clearly shows the hollow nature of the synthesized $\mathrm{ZnO} \mathrm{NWs}$. However, the surfaces of the hollow $\mathrm{ZnO}$ NWs prepared using the membrane with a pore diameter of $0.4 \mu \mathrm{m}$ had bead-like humps, which obviously increased the surface area of this sample. The inset in this figure again shows the hollow nature of the $\mathrm{ZnO}$ NWs.

\subsection{Gas sensing study}

The temperature is one of the most important parameters affecting the sensing behavior of a sensor. This is because of the fact that the adsorption, reaction, and desorption phenomena are strongly dependent on the temperature [19]. In order to determine the optimal working temperature, the higher surface area $\left(10.17 \mathrm{~m}^{2} \mathrm{~g}^{-1}\right)$ gas sensor was exposed to 1 and $10 \mathrm{ppm}$ of $\mathrm{CO}$ gas at different temperatures. Figure 3a shows the normalized resistance curves of the sensor for 1 and $10 \mathrm{ppm}$ of $\mathrm{CO}$ over the temperature range of $250-400{ }^{\circ} \mathrm{C}$. Notably, the resistance of the sensor decreased when $\mathrm{CO}$ gas was supplied and increased when the supply was discontinued. This clearly indicates n-type behavior of the gas sensor, originating from the n-type nature of $\mathrm{ZnO}$ as a result of oxygen defects in the structure of $\mathrm{ZnO}$. At $250{ }^{\circ} \mathrm{C}$, there was no noticeable response to $\mathrm{CO}$ gas. At 300 and $350{ }^{\circ} \mathrm{C}$, even though the response was higher than that at $250^{\circ} \mathrm{C}$, the response was still not significant. However, at $400{ }^{\circ} \mathrm{C}$, a significant response was observed. Therefore, $400{ }^{\circ} \mathrm{C}$ was determined as the optimal sensing temperature.
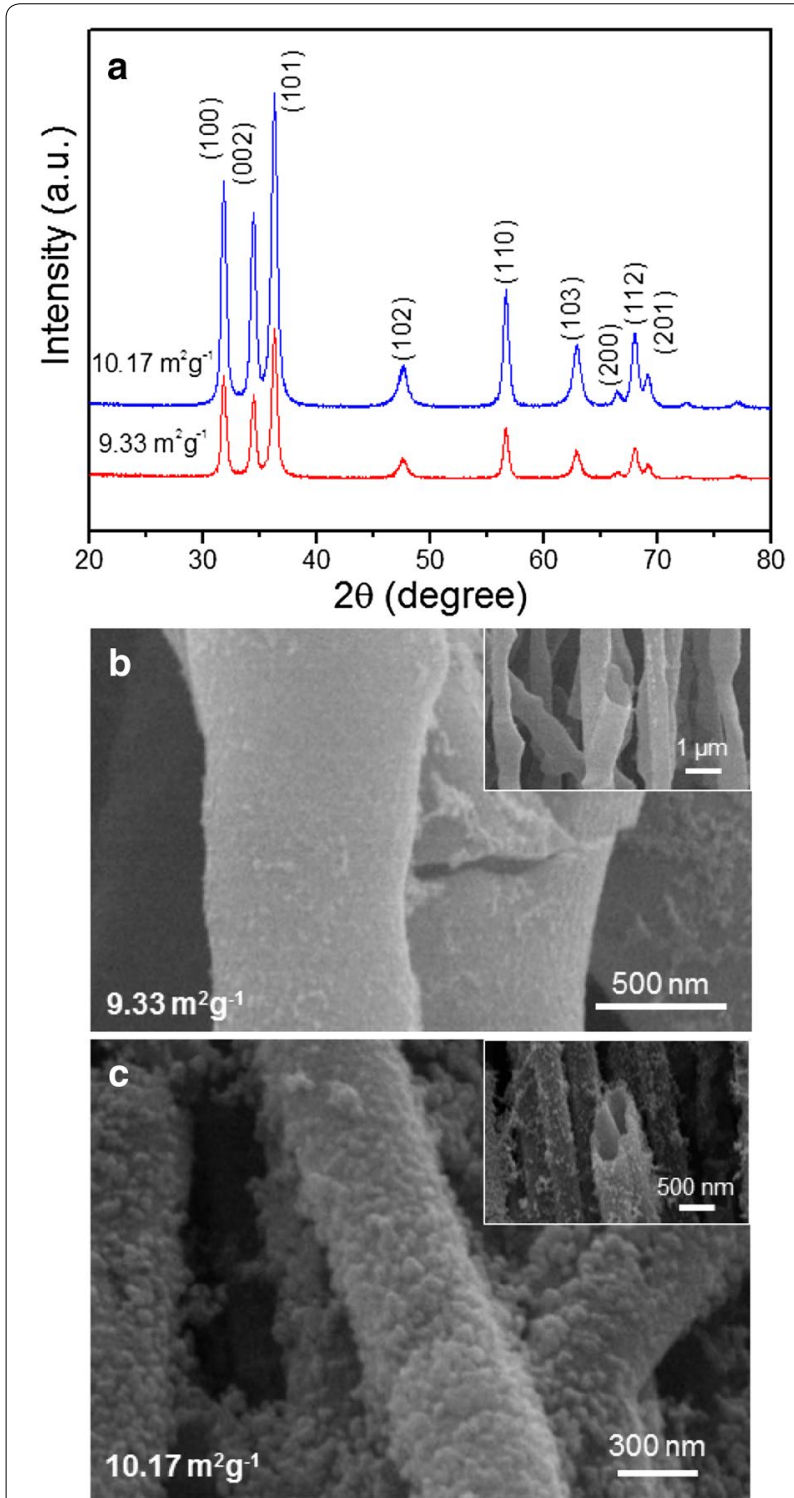

Fig. 2 a XRD patterns of hollow ZnO NWs. FE-SEM images of hollow ZnO NWs with different surface areas: b $9.33 \mathrm{~m}^{2} \mathrm{~g}^{-1} \cdot \mathbf{c} 10.17 \mathrm{~m}^{2} \mathrm{~g}^{-1}$ 


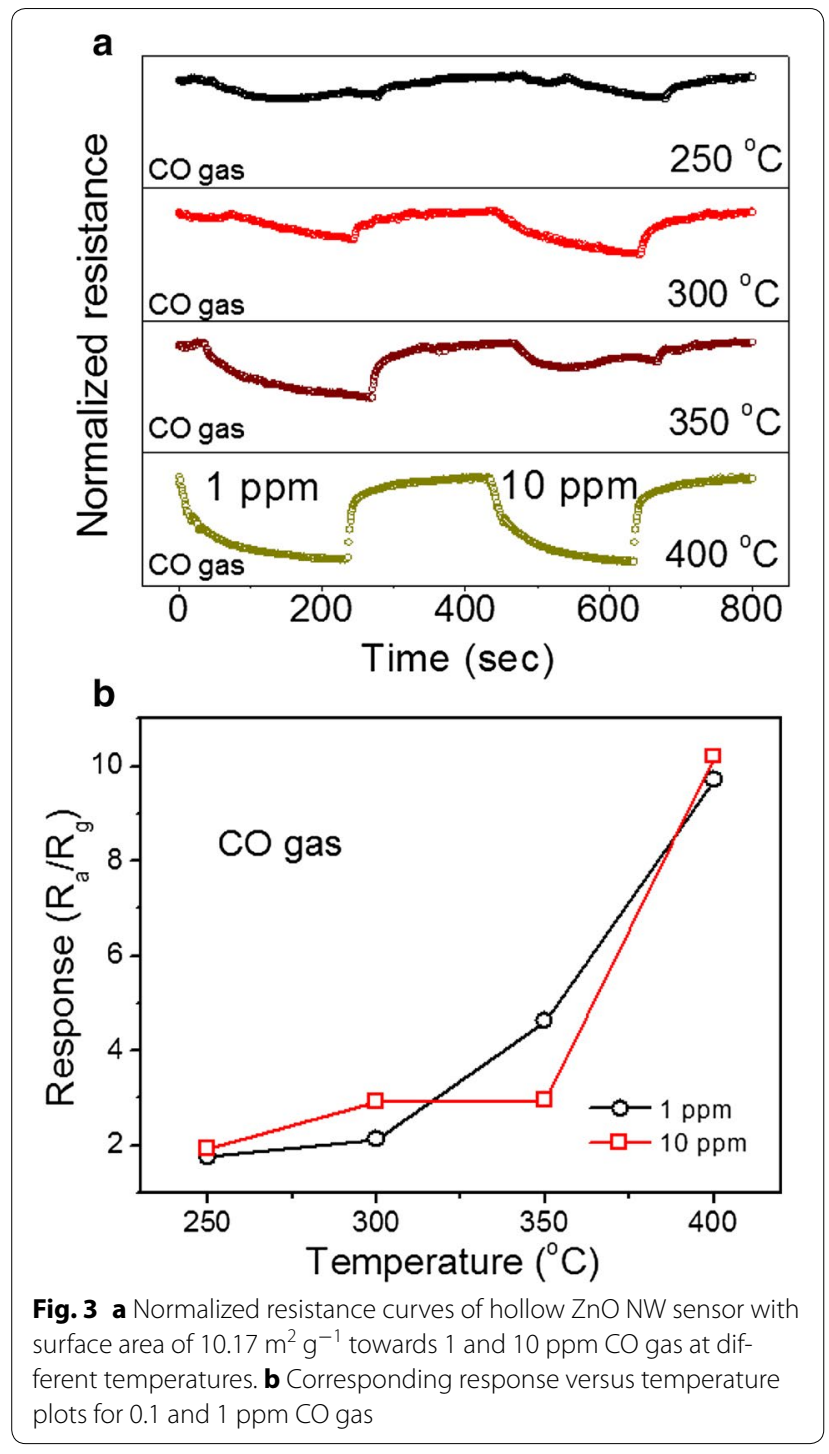

Figure $3 \mathrm{~b}$ shows the plot of the gas response versus the sensing temperature. The low response of the gas sensor at lower temperatures is due to insufficient energy for the adsorption and reaction phenomena on the surface of the sensor.

Figure $4 \mathrm{a}, \mathrm{b}$ display the dynamic normalized resistance curves of the $\mathrm{ZnO} \mathrm{NW}$ sensors with different surface areas upon exposure to $0.1,1$, and $10 \mathrm{ppm}$ of $\mathrm{CO}$ and $\mathrm{NO}_{2}$ gases, respectively, at $400{ }^{\circ} \mathrm{C}$. Because $\mathrm{NO}_{2}$ is an oxidizing gas, the resistance of the sensors will increase upon exposure to $\mathrm{NO}_{2}$ gas. Figure $4 \mathrm{c}$ shows the response of both gas sensors versus the surface area when exposed to different concentrations of gaseous $\mathrm{NO}_{2}$ and $\mathrm{CO}$. The response of both sensors towards $\mathrm{NO}_{2}$ was much higher than the response to $\mathrm{CO}$ gas; furthermore, the gas response increased with increasing gas concentration
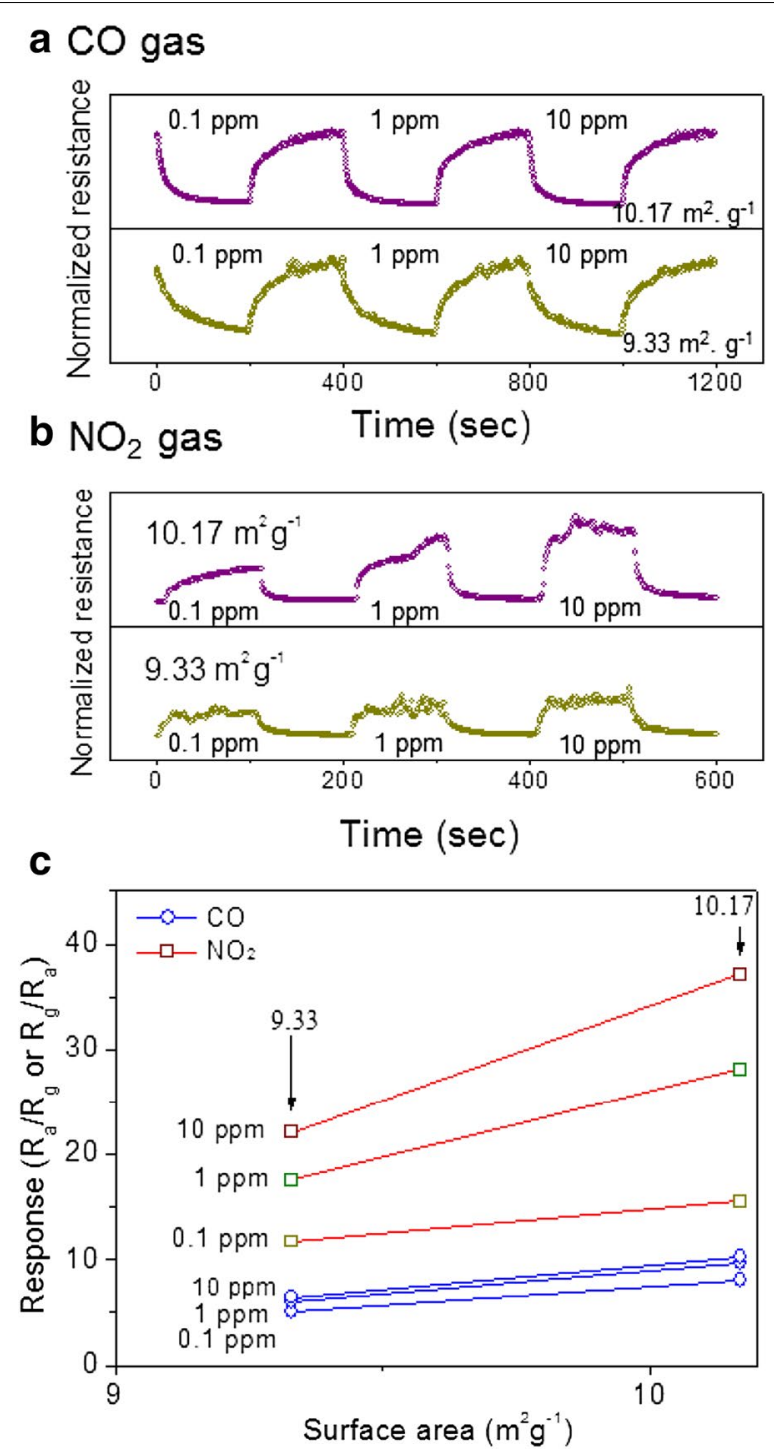

Fig. 4 Normalized resistance curves of hollow $\mathrm{ZnO}$ NW sensors with different surface areas towards $0.1,1$, and $10 \mathrm{ppm}$ of $\mathbf{a} \mathrm{CO}$ and $\mathbf{b} \mathrm{NO}_{2}$ at $400^{\circ} \mathrm{C}$. c Response versus surface area for hollow $\mathrm{ZnO}$ NWs sensor with different surface areas at different concentrations of $\mathrm{CO}$ and $\mathrm{NO}_{2}$ gases

for both gases. Moreover, the gas sensor with the higher surface area showed a higher response to both $\mathrm{NO}_{2}$ and $\mathrm{CO}$. Because the gas adsorption phenomenon is strongly dependent on the surface area, the sensor with the higher surface area can provide more adsorption sites for the target gases, and therefore, as expected, the sensor with the higher surface area $\left(10.17 \mathrm{~m}^{2} \mathrm{~g}^{-1}\right)$ showed better sensing performance than the sensor with the lower surface area $\left(9.33 \mathrm{~m}^{2} \mathrm{~g}^{-1}\right)$.

The gas sensing mechanism of metal-oxide based gas sensors is based on a change in the resistance upon gas 
adsorption and desorption. In air, oxygen gas will be adsorbed on the surface of the sensor, and owing to its high electron affinity, oxygen can extract electrons from the conduction band of $\mathrm{ZnO}$ to form various oxygen ions according to the following reactions:

$$
\begin{aligned}
& \mathrm{O}_{2}(g) \rightarrow \mathrm{O}_{2}(\text { ads }) \\
& \mathrm{O}_{2}(a d s)+e^{-} \rightarrow \mathrm{O}_{2}^{-} \\
& \mathrm{O}_{2}^{-}(\text {ads })+e^{-} \rightarrow 2 O^{-} \\
& \mathrm{O}_{2}(\text { ads })+e^{-} \rightarrow \mathrm{O}^{2-}
\end{aligned}
$$

It is reported that the $\mathrm{O}_{2}^{-}, \mathrm{O}^{-}$, and $\mathrm{O}^{2-}$ ions are respectively stable at $<150,150-300$, and $>300{ }^{\circ} \mathrm{C}[20,21]$. Herein, the sensing temperature was $400{ }^{\circ} \mathrm{C}$; thus, it can be reasonably supposed that the dominant oxygen species on the surface of the sensor was $\mathrm{O}^{2-}$. Abstraction of electrons from the surface of $\mathrm{ZnO}$ by oxygen leads to the formation of an electron depleted layer (EDL) on the inner and outer surfaces of the sensor, and the width of the conduction channel is proposed to be $D_{1}$, as shown in Fig. 5a.

When the $\mathrm{ZnO}$ sensor is exposed to $\mathrm{NO}_{2}$ gas, $\mathrm{NO}_{2}$ can directly take electrons from the surface of the sensor or can react with the adsorbed oxygen species on the surface of the sensor [21] as follows [22, 23]:

$$
\begin{aligned}
& \mathrm{NO}_{2}+e^{-} \rightarrow \mathrm{NO}_{2}^{-} \\
& \mathrm{NO}_{2}^{-}+\mathrm{O}^{2-}+e^{-} \rightarrow \mathrm{NO}(g)+2 \mathrm{O}^{2-}
\end{aligned}
$$

These reactions will result in a decrease in the electron concentration and an increase in the width of the depletion layer, and an increase in the resistance (see Fig. 5b). Accordingly, the width of the conduction channel decreases to $D_{2}$, which is smaller than $D_{1}$ (in air), and a high response can be observed.

Upon exposure of the sensor to $\mathrm{CO}$ gas, the gas reacts with adsorbed electrons on the surface of the sensor according to the following reaction [24]:

$$
\mathrm{CO}+\mathrm{O}^{2-} \rightarrow \mathrm{CO}(\text { gas })+2 e^{-}
$$

The released electrons return to the surface of the $\mathrm{ZnO}$ sensor, increasing the width of the depletion layers on the inner and outer surfaces of $\mathrm{ZnO}$; the width of the conduction channel will increase to $D_{3}$, which is larger than $D_{1}$. Accordingly, the resistance will decrease (see Fig. 5c). For $\mathrm{ZnO} \mathrm{NWs}$-based gas sensors, the modulation of depletion layers in the presence of target gas, has been reported in many papers. For instance, Choi et al. [25] reported modulation of depletion layers in the networked $\mathrm{ZnO}$ NWs in the presence of CO gas. Drobek et al. [26] reported modulation of depletion layers in pristine $\mathrm{ZnO}$

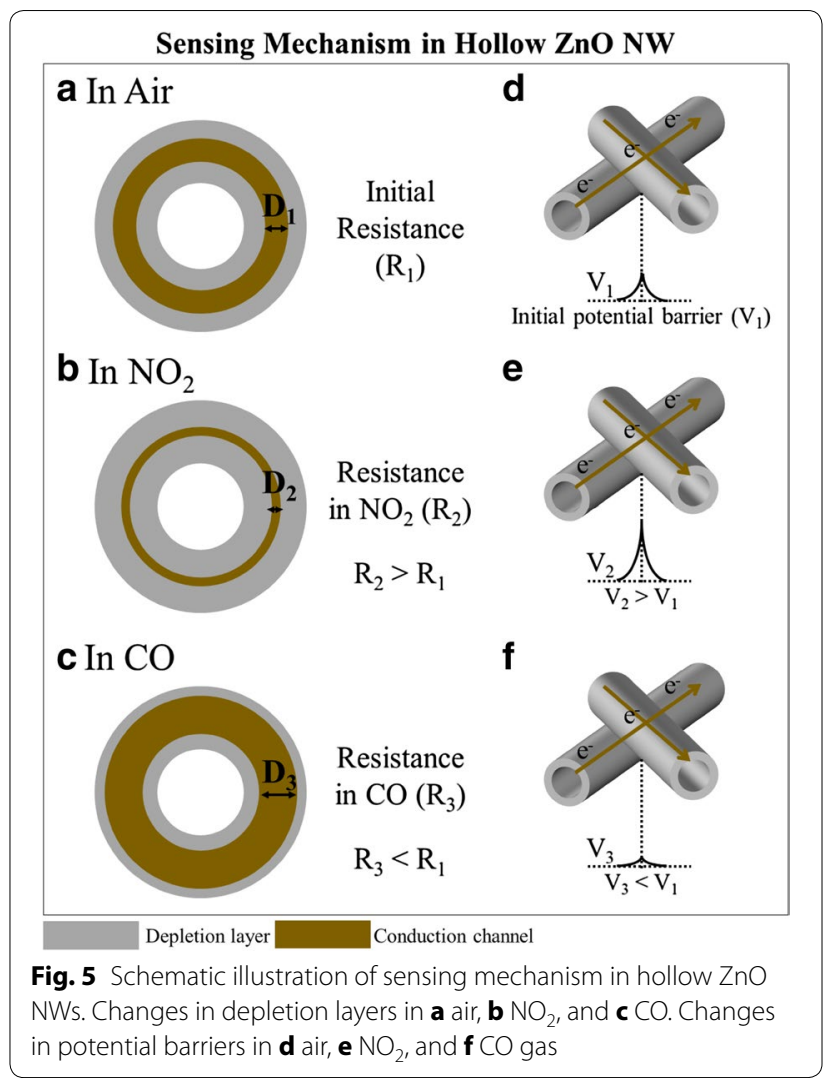

and ZnO@ZIF-8 composite NWs in the presence of some reducing gases. Additionally, for other metal oxide NWs such as $\mathrm{SnO}_{2}$ NWs [27] and $\mathrm{In}_{2} \mathrm{O}_{3}$ NWs [28], the same sensing mechanism has been proposed.

Resistance modulation may also arise from homojunctions formed as a result of intersections between the hollow ZnO NFs. As shown in Fig. $5 \mathrm{~d}-\mathrm{f}$, when the sensor is exposed to $\mathrm{NO}_{2}$ gas, the initial potential barrier in $\mathrm{V}_{1}$ will increase to $\mathrm{V}_{2}$, and upon exposure to $\mathrm{CO}$ gas, it decreases to $V_{3}$, which is lower than V1. These resistance modulations eventually contribute to observation of a response in the sensors.

The higher response to $\mathrm{NO}_{2}$ relative to $\mathrm{CO}$ may be related to the high electron affinity of $\mathrm{NO}_{2}(2.28 \mathrm{eV})$ in comparison with that of adsorbed oxygen $(0.43 \mathrm{eV})$ [29]. $\mathrm{NO}_{2}$ is a strongly oxidizing gas that can extract electrons from the exposed surfaces of the hollow $\mathrm{ZnO}$ NFs and significantly decreases the width of the electron depletion layers.

Table 1 presents a comparison of some $\mathrm{ZnO}$-based gas sensors for the detection of $\mathrm{NO}_{2}$ gas with that of the present hollow ZnO NWs sensor. As is evident, the developed sensor based on membrane template-grown $\mathrm{ZnO}$ NWs shows a better response towards $\mathrm{NO}_{2}$. In particular, the developed sensor showed a response of 15.5 to 
Table 1 Comparison of the $\mathrm{NO}_{2}$ gas sensing properties of the present sensor (with specific surface area of $10.17 \mathrm{~m}^{2} \mathrm{~g}^{-1}$ ) with those of other $\mathrm{ZnO}$-based gas sensors reported in the literature

\begin{tabular}{|c|c|c|c|c|}
\hline Sensor & $\mathrm{NO}_{2}$ conc. (ppm) & $T\left({ }^{\circ} \mathrm{C}\right)$ & Response $\left(R_{a} / R_{g}\right)$ & References \\
\hline Hollow ZnO NWs & 0.1 & 400 & 15.5 & This study \\
\hline Hollow ZnO NWs & 10 & 400 & 37.1 & This study \\
\hline Branched ZnO NWs & 5 & 300 & 1.06 & [19] \\
\hline ZnO-decorated MWCNTs & 10 & 300 & 1.023 & [20] \\
\hline $\mathrm{ZnO/graphene} \mathrm{nanocomposites}$ & 1 & 300 & 12.57 & [21] \\
\hline CNT-ZnO nanocomposite & 20 & 250 & 1.19 & [31] \\
\hline $\mathrm{SnO}_{2}$-core/ZnO-shell NFs & 5 & 300 & 1.5 & {$[32]$} \\
\hline $\mathrm{SnO}_{2}-\mathrm{ZnO}-\mathrm{Co} \mathrm{NWs}$ & 10 & 300 & 7.48 & [33] \\
\hline $\mathrm{Zn}_{2} \mathrm{SnO}_{4} / \mathrm{ZnO}$ nanorods & 1 & 300 & 1.70 & [34] \\
\hline ZnO brushes & 50 & 300 & 1.2 & {$[35]$} \\
\hline $\mathrm{ZnGa}_{2} \mathrm{O}_{4}$-core/ZnO-shell NWs & 1 & 250 & 2.6 & {$[36]$} \\
\hline ZnO nanoparticles & 1 & 150 & 13.7 & {$[30]$} \\
\hline $\mathrm{ZnO}$ nanorods & 50 & 225 & 35 & {$[37]$} \\
\hline $\mathrm{ZnO}$ nanorods & 5 & 175 & 20 & {$[38]$} \\
\hline ZnO-reduced graphene oxide & 5 & 25 & 2.5 & [39] \\
\hline Flower-like $\mathrm{ZnO}\left(4.9 \mathrm{~m}^{2} \mathrm{~g}^{-1}\right)$ & 100 & 25 & 12.27 & [40] \\
\hline
\end{tabular}

$0.1 \mathrm{ppm} \mathrm{NO}_{2}$, whereas the response of branched $\mathrm{ZnO}$ NWs to 5 ppm was 1.06 [19]. Further, the response of the $\mathrm{ZnO}$ nanoparticles towards $1 \mathrm{ppm} \mathrm{NO}_{2}$ was 13.7 [30]. This high response observed in the present hollow $\mathrm{ZnO}$ NWs sensor can be mainly attributed to the high surface area of the synthesized hollow ZnO NFs, where the inner and outer surfaces both provide numerous adsorption sites for $\mathrm{NO}_{2}$ gas. One paper [40] listed in Table 1 reports the value of specific surface area of sensor materials. Flower-like $\mathrm{ZnO}$ revealed a specific surface area of $4.9 \mathrm{~m}^{2} \mathrm{~g}^{-1}$, supporting the high surface area of the hollow $\mathrm{ZnO}$ NFs. However, the sensing temperature used herein is relatively high in comparison with those of the other sensors.

\section{Conclusion}

In summary, a novel approach was applied to the fabrication of hollow ZnO NWs with different specific surface areas. Cyclopore polycarbonate membranes with different pore sizes were used as templates and $\mathrm{ZnO}$ was deposited on these templates via the ALD technique. Because of the simplicity of this method, it can be easily applied to other oxide semiconductors. The prepared hollow $\mathrm{ZnO}$ NWs had respective surface areas of 9.33 and $10.17 \mathrm{~m}^{2} \mathrm{~g}^{-1}$. Gas sensors were fabricated from the hollow $\mathrm{ZnO} \mathrm{NWs}$, and the gas sensing properties were investigated in the presence of $\mathrm{CO}$ and $\mathrm{NO}_{2}$ gases. The sensor with a surface area of $10.17 \mathrm{~m}^{2} \mathrm{~g}^{-1}$ showed excellent sensing of $\mathrm{NO}_{2}$ at $400{ }^{\circ} \mathrm{C}$ relative to the lower surface area gas sensor; the responses to $0.1,1$, and $10 \mathrm{ppm} \mathrm{NO}_{2}$ were $15.5,28.06$, and 37.1 , respectively.

\section{Authors' contributions}

J-HL, J-YK and J-HK carried out the synthesis of how NWs, device fabrication and measurement. AM, HWK and SSK wrote the manuscript. SSK supervised the research. All authors read and approved the final manuscript.

\section{Competing interests}

The authors declare that they have no competing interests.

\section{Funding}

This research was supported by the Basic Science Research Program through the National Research Foundation of Korea (NRF) funded by the Ministry of Education (2016R1D1A1B03935228).

\section{Publisher's Note}

Springer Nature remains neutral with regard to jurisdictional claims in published maps and institutional affiliations.

Received: 19 August 2017 Accepted: 4 October 2017 Published online: 25 October 2017

\footnotetext{
References

1. A. Mirzaei, S.G. Leonardi, G. Neri, Ceram. Int. 42, 15119-15141 (2016)

2. S.K. Pandey, K.H. Kim, K.T. Tang, TrAC. Trends Anal. Chem. 32, 87-99 (2012)

3. A. Mirzaei, K. Janghorban, B. Hashemi, G. Neri, J. Nanopart. Res. 17, 1-36 (2015)

4. G.J. Li, X.H. Zhang, S. Kawi, Sens. Actuators B 60, 64-70 (1999)

5. J.-H. Kim, Y. Zheng, A. Mirzaei, S.S. Kim, Korean. J. Mater. Res. 26, 741-750 (2016)

6. J. Xu, Y. Chen, Y. Li, J. Shen, J. Mater. Sci. 40, 2919-2921 (2005)

7. Y.J. Kwon, H.G. Na, S.Y. Kang, M.S. Choi, J.H. Bang, T.W. Kim, A. Mirzaei, H.W. Kim, Sens. Actuators B 239, 180-192 (2017)

8. X.X. Yu, X.S. Liu, M.Z. Wu, Z.Q. Sun, X.S. Chen, Chin. J. Chem. Phys. 27, 99-102 (2014)

9. J. Zhang, S. Wang, M. Xu, Y.D. Wang, B.L. Zhu, S. Zhang, W. Huang, S. Wu, Cryst. Growth Des. 9, 3532-3537 (2009)

10. J.Y. Park, S.W. Choi, S.S. Kim, Nanotechnology 21, 475601-475610 (2010)
} 
11. A. Katoch, Z.U. Abideen, J.-H. Kim, S.S. Kim, Sens. Actuators B 232, 698-704 (2016)

12. A. Katoch, S.W. Choi, S.S. Kim, Nanotechnology 25, 455504-455511 (2014)

13. A. Katoch, J.-H. Kim, S.S. Kim, ACS Appl. Mater. Interfaces 6, 21494-21499 (2014)

14. J. Zhang, S.W. Choi, S.S. Kim, J. Solid State Chem. 184, 3008-3013 (2011)

15. X. Chen, C.K.Y. Wong, C.A. Yuan, G. Zhang, Sens. Actuators B 177, 178-195 (2013)

16. J.-H. Kim, H.W. Kim, S.S. Kim, Sens. Actuators B 239, 578-585 (2017)

17. J.-H. Kim, J.-H. Lee, A. Mirzaei, H.W. Kim, S.S. Kim, Sens. Actuators B 248 500-511 (2017)

18. J.-H. Kim, Y. Zheng, A. Mirzaei, H.W. Kim, S.S. Kim, J. Electron. Mater. 46 3531-3541 (2017)

19. Y.J. Kwon, S.Y. Kang, A. Mirzaei, M.S. Choi, J.H. Bang, S.S. Kim, H.W. Kim, Sens. Actuators B 249, 656-666 (2017)

20. Y.J. Kwon, A. Mirzaei, S.Y. Kang, M.S. Choi, J.H. Bang, S.S. Kim, H.W. Kim, Appl. Surf. Sci. 413, 242-252 (2017)

21. H.W. Kim, Y.J. Kwon, A. Mirzaei, S.Y. Kang, M.S. Choi, J.H. Bang, S.S. Kim, Sens. Actuators B 249, 590-601 (2017)

22. A. Mirzaei, K. Janghorban, B. Hashemi, M. Bonyani, S.G. Leonardi, G. Neri, Ceram. Int. 42, 18974-18982 (2016)

23. Y.J. Kwon, A. Mirzaei, H.G. Na, S.Y. Kang, M.S. Choi, J.H. Bang, J. Lee, I.P. Kang, S.S. Kim, H.W. Kim, Korean J Met. Mater. 55, 492-502 (2017)

24. A. Mirzaei, S. Park, G.J. Sun, H. Kheel, C. Lee, J. Hazard. Mater. 305, 130-138 (2016)

25. S.W. Choi, S.S. Kim, Sens. Actuators B 168, 8-13 (2012)
26. M. Drobek, J.H. Kim, M. Bechelany, C. Vallicari, A. Julbe, S.S. Kim, ACS Appl. Mater. Interfaces 8(13), 8323-8328 (2016)

27. H.W. Kim, S.W. Choi, A. Katoch, S.S. Kim, Sens. Actuators B 177, 654-658 (2013)

28. S.S. Kim, J.Y. Park, S.W. Choi, H.G. Na, J.C. Yang, H.W. Kim, J. Alloys Compd. 509(37), 9171-9177 (2011)

29. A.A. Manea, M.P. Suryawanshi, J.H. Kim, A.V. Moholkar, J. Colloid Interface Sci. 483, 220-231 (2016)

30. V.L. Patil, S.A. Vanalakara, P.S. Patil, J.H. Kim, Sens. Actuators B 239 , 1185-1193 (2017)

31. R. Vyas, S. Sharma, P. Gupta, A.K. Prasad, A.K. Tyagi, K. Sachdev, S.K. Sharma, Adv. Mater. Res. 585, 235-239 (2012)

32. S.W. Choi, J.Y. Park, S.S. Kim, Nanotechnology 20, 465603-465608 (2009)

33. H.W. Kim, H.G. Na, H.Y. Cho, C. Lee, Sens. Actuators B 219, 22-29 (2015)

34. S. Park, S. An, H. Ko, C. Jin, C. Lee, Ceram. Int. 39, 3539-3545 (2013)

35. Y.M. Zhang, J. Xu, Q. Xiang, H. Li, Q. Pan, P. Xu, J. Phys. Chem. C 113, 3430-3435 (2009)

36. I.C. Chen, S.S. Lin, T.J. Lin, C.L. Hsu, T.J. Hsueh, T.Y. Shieh, Sensors 10 3057-3072 (2010)

37. X. Wang, F. Sun, Y. Duan, Z. Yin, W. Luo, Y. Huang, J. Chen, J. Mater. Chem. C 3, 11397-11405 (2015)

38. S.A. Vanalakar, V.L. Patil, N.S. Harale, S.A. Vhanalakar, M.G. Gang, J.Y. Kim, P.S. Atil, J.H. Kim, Sens. Actuators B 221, 1195-1201 (2015)

39. S. Liu, B. Yu, H. Zhang, T. Fei, T. Zhang, Sens. Actuators B 202, 272-278 (2014)

40. P. Rai, S. Raj, K.J. Ko, K.K. Park, Y.T. Yu, Sens. Actuators B 178, 107-112 (2013)

\section{Submit your manuscript to a SpringerOpen ${ }^{\circ}$ journal and benefit from:}

- Convenient online submission

- Rigorous peer review

- Open access: articles freely available online

- High visibility within the field

- Retaining the copyright to your article

Submit your next manuscript at springeropen.com 